\title{
Competência crítica em informação como prática de ensino: panorama de pesquisas a partir de trabalhos presentes na BRAPCI e na BDTD
}

\author{
Critical information literacy as a teaching practice: overview of research available on \\ $B R A P C I$ and BDTD
}

\author{
Andréa Doyle \\ Doutora em Ciência da Informação \\ Instituto Brasileiro de Informação em Ciência e Tecnologia \\ andrea@hibrida.art.br
}

\begin{abstract}
Resumo
Em 2015, enquanto Eamon Tewell publica um artigo de revisão de uma década de estudos de critical information literacy nos Estados Unidos da América, o termo competência crítica em informação aparece pela primeira vez em Português. A presente pesquisa, um levantamento bibliográfico de natureza descritiva e exploratória, olha para os estudos sobre competência crítica em informação (CCl) com o objetivo de apresentar seus temas de pesquisa e compreender suas características, especialmente com relação ao ensino de tais competências. Os dados coletados, na Base de Dados Referencial de Artigos de Periódicos em Ciência da Informação (BRAPCI) e na Biblioteca Digital de Teses e Dissertações (BDTD), indicam 23 artigos e 3 dissertações de mestrado sobre o tema. Esses trabalhos são analisados a partir de suas temáticas e dos tipos de pesquisa (teórica, empírica ou aplicada) realizadas nesses primeiros 5 anos de desenvolvimento do campo. Os resultados das dissertações indicam que a CCl trabalha na interseção entre informação, política e emancipação. Já a análise dos artigos mostra que ainda não há pesquisa sobre ensino de competência crítica em informação no país. Os temas mais explorados nos trabalhos são ética, desinformação, bibliotecas, práticas informacionais, teorias críticas, movimentos sociais e regimes de informação. Conclui-se que a ideia de competência crítica em informação discute fundamentos e temas que estimulam um olhar questionador para a realidade informacional contemporânea, mas ainda precisa ganhar capilaridade na academia, em unidades de informação e em salas de aula para que se criem práticas de ensinoaprendizagem voltadas para a promoção um relacionamento crítico com o ambiente informacional.
\end{abstract}

\section{Palavras-chave}

Competência crítica em informação. Ciência da Informação. Pedagogia crítica. Práticas de ensinoaprendizagem. Competência em Informação.

\begin{abstract}
In 2015, while Eamon Tewell published an article reviewing a decade of critical information literacy studies in the United States of America, the term critical information literacy appears for the first time in Portuguese. This research, a bibliographical review of descriptive and exploratory nature, looks at studies on critical information literacy (CIL) with the aim of understanding its characteristics, particularities and potential in the country, especially regarding the teaching of such competences. The data collected in the Reference Database of Journal Articles in Information Science (BRAPCI) and in the Digital Library of Theses and Dissertations (BDTD), indicate 23 articles and 3 master's dissertations on the subject. These works are analyzed by theme and type of research (theoretical, empirical or ap-


plied) carried out in these first 5 years of field development. The results of the dissertations indicate that the CIL works at the intersection between information, politics and emancipation. The analysis of the articles shows that there is still no research on the teaching of critical information literacy in the country. The most explored themes in the works are ethics, disinformation, libraries, informational practices, critical theories, social movements and information regimes. It is concluded that the idea of critical information literacy discusses fundamentals and themes that encourage a questioning look at the contemporary informational reality, but it still needs to gain capillarity in the academy, in information units and in classrooms so that teaching-learning practices aimed at promoting a critical relationship with the informational environment can be proposed.

\section{Keywords}

Critical information literacy. Information Science. Critical pedagogy. Teaching-learning practices. Information Skills.

\section{INTRODUÇÃO}

Em 2015, enquanto Eamon Tewell publica um artigo de revisão de uma década de estudos de critical information literacy nos Estados Unidos da América, o termo competência crítica em informação aparece pela primeira vez em Português. Ao nosso entender, competência crítica em informação é o desenvolvimento contínuo de um relacionamento questionador e libertador com a informação e com os diversos aspectos do ambiente informacional (DOYLE, 2021).

No Brasil, a primeira menção à subárea de estudos chamada em inglês de critical information literacy foi em um artigo de revisão do conceito de competência em informação das bibliotecárias Elizete Vitorino e Daniela Piantola (2009), em que dedicam uma seção do artigo ao que chamam de competência informacional crítica. Elas começam pelos pioneiros Jeremy Shapiro e Shelley Hughes (1996, p. 2, tradução nossa) e seu questionamento sobre que tipo de habilidade informacional as pessoas precisam desenvolver: domínio de tecnologias, técnicas de busca ou "pensar criticamente sobre toda a construção informacional e sobre a sociedade da informação"?

Na sequência, Vitorino e Piantola (2009) citam autores que se tornaram referências incontornáveis como James Elmborg (2006) e John Doherty (2007), sublinhando que o primeiro destaca a influência direta da pedagogia de Paulo Freire na proposta de educação para a autonomia nas bibliotecas. Já o segundo fala de dar voz aos silenciados, uma questão que também foi trabalhada pelo educador que considerava o silêncio uma forte marca da opressão objetificadora.

As autoras comentam o legado da Teoria Crítica da Escola de Frankfurt como base para uma visão não neutra da ciência, ou seja, que entende a produção científica como uma atividade humana contextualizada sócio-historicamente, que pode reforçar as estruturas de poder e dominação ou trabalhar para desconstruí-las. Elas também mencionam o trabalho de Dane Ward (2006) e Sherry Crow (2007) que falam de aspectos afetivos, de inspiração e motivação, fundamentais para o aprendizado significativo ao longo da vida. As autoras concluem que o conceito envolve uma "complexa gama de processos individuais e coletivos, constituindo um campo fértil de pesquisa e de ação de potencial transformador." (VITORINO, PIANTOLA, 2009, p. 138)

Em 2015, o termo "competência crítica em informação" aparece pela primeira vez em um artigo apresentado no Enancib (BEZERRA, 2015, p.3) sobre os algoritmos das 
plataformas digitais, que vigiam o comportamento de quem as utiliza e registram esse histórico para filtrar e ordenar o acesso a conteúdos na internet. O trabalho mobiliza o conceito para propor que a compreensão do funcionamento e do poder das plataformas também comporia uma competência crítica em informação.

A partir daí, diversos trabalhos começam a abordar a competência crítica em informação, delineando uma nova linha de pesquisa. O objetivo do presente artigo é destacar a produção científica nacional em torno do conceito de competência crítica em informação para sistematizar um panorama de suas características gerais, mas principalmente, para identificar trabalhos que discutam o ensino dessas competências críticas. Pretendemos, prioritariamente, verificar a premissa de que o campo ainda está numa fase mais teórica de desenvolvimento e que não há, ainda, pesquisas dedicadas ao ensino dessa competência crítica.

Vale destacar que o presente artigo é fruto de pesquisa exploratória feita em fevereiro de 2021 para embasar a tese de doutorado "Competências em informação, mídias e tecnologias digitais e a desconstrução de estereótipos de gênero: práticas de ensino críticas" (DOYLE, 2021). Enquanto ele estava sendo avaliado, Renata Furtado e co-autoras (FURTADO; INOMATA; COSTA; CAVALCANTI; LISBOA, 2021) publicaram um artigo de revisão chamado "Panorama brasileiro sobre os estudos de competência crítica em informação". Trata-se de um extenso trabalho de revisão de literatura, levantada na Base de Dados Referencial de Artigos de Periódicos em Ciência da Informação (BRAPCI), com foco na análise bibliométrica e na análise sistêmica.

A existência de dois panoramas sobre o mesmo assunto, publicados quase ao mesmo tempo, denota uma grande curiosidade do campo pelo tema. Se, por um lado, o corpus de análise encontrado é muito semelhante (as metodologias de coleta muito próximas geraram resultados quase idênticos), por outro lado, os objetivos das pesquisas e, consequentemente, suas linhas analíticas são distintas e complementares.

Os resultados obtidos pela equipe de Renata Furtado "mostram os autores, periódicos e instituições que estão desenvolvendo essa abordagem, assim como, o perfil do conteúdo dos textos e a contribuição que cada estudo pode trazer para a sociedade no que diz respeito às necessidades informacionais vinculadas ao pensamento crítico." (FURTADO; INOMATA; COSTA; CAVALCANTI; LISBOA, 2021, p. 824). Já nosso foco aqui é examinar que tipo de pesquisa os estudos sobre competência crítica em informação estão desenvolvendo e se o ensino dessas competências críticas está sendo explorado ou praticado.

Para tanto, iniciamos com esta introdução, estabelecendo, como tema, o aparecimento do conceito e do termo na Ciência da Informação (Cl) brasileira. Em seguida, contextualizaremos o campo nos Estados Unidos da América, depois apresentaremos a metodologia utilizada na pesquisa. Na sequência, os resultados são descritos e seguidos de uma discussão sobre as particularidades da pesquisa sobre competência crítica em informação já desenvolvida no país.

\section{CRITICAL INFORMATION LITERACY NAS BIBLIOTECAS ESTADUNIDENSES}

A partir da virada do milênio, grupos de profissionais de biblioteconomia estadunidenses responsáveis por ensinar competência em informação começam a questionar o alcance e o interesse dessas formações. Aprender a buscar referências bibliográficas e a avaliar sua adequação para a pesquisa acadêmica significa ter preparo para lidar com a informação? O método de treinamentos pode gerar, de fato, um aprendizado 
para a vida? A informação pode ser entendida como coisa a ser obtida, selecionada, avaliada e usada? O movimento de crítica ao modelo entendido como tecnicista e as buscas por novas formas de ensinar ficou conhecido como critical information literacy.

Anne Downey (2016) entende que, em reação a um modelo único e massificado, começou-se a pensar por um lado, no acolhimento de determinados grupos historicamente excluídos das comunidades acadêmicas. Particularidades como identidades (étnico-racial, gênero, sexualidade, entre outras), língua materna, condições sócio-econômicas, por exemplo, passam a ser consideradas, para que toda a comunidade possa prosperar. Por outro lado, voltou-se também o olhar para o modo como informações são produzidas, validadas e disponibilizadas, assim como para as arbitrariedades ligadas a ele.

Para lidar com as questões envolvendo o ensino de habilidades informacionais mecânicas e simplificadas demais, em um contexto de mundo cheio de informações confusas e amplamente corporativistas, um crescente número de bibliotecários começou a estudar e a ensinar um novo sub-conjunto de competência em informação, chamado de competência crítica em informação, que olha para as estruturas culturais, sociais e econômicas subjacentes à toda produção e disseminação da informação (DOWNEY, 2016, p. 18, tradução nossa).

Incialmente, a competência crítica em informação aparece como um contraponto ao entendimento de competência em informação. A área olha para si mesma, se perguntando se seus objetivos permanecem válidos e que práticas precisam/podem ser melhoradas. Maria Accardi, Emily Drabinski e Alana Kumbier organizam, em 2010, um livro que compila teorias e práticas críticas de ensino em bibliotecas. Na introdução, as autoras propõem a seguinte definição para competência crítica em informação.

Competência crítica em informação é uma práxis de ensino em bibliotecas que promove um engajamento crítico com fontes de informação, considera estudantes como colaboradores em práticas de produção de conhecimento (e criadores em seu próprio direito), reconhece as dimensões afetivas da pesquisa e (em alguns casos) tem objetivos libertadores (ACCARDI, DRABINSKI; KUMBIER, 2010, p. xi, tradução nossa ${ }^{1}$ ).

Quando olhamos pelo ângulo da $\mathrm{Cl}$, e partirmos da informação e não do ensino, entendemos competência crítica em informação (CCl) como um estado de eterno alerta, sempre vigilante no trato com a informação, que se pergunta constantemente, entre outras questões: Quem produziu essa informação? Com que intenção? Quando e com que condições? Com que dificuldades/facilidades? Quem financiou isso (e com que intenção)? Por onde ela passou? Como chegou até mim? Que grupos ela representa e quais ela silencia? Que outras informações parecidas/diferentes não chegaram até mim no lugar dessa e por quê? Este costuma ser o nosso foco de trabalho, ou seja, o detalhamento da segunda parte da definição: "um engajamento crítico com fontes de informação".

Sobre a práxis de ensino, diversos teóricos da CCI (ELMBORG, 2006; DOWNEY, 2016; TEWELL, 2015) sublinham a influência da pedagogia crítica de Paulo Freire (1987). As principais ideias norteadoras dessa abordagem são a noção de que o/a estudante é um sujeito inteligente rico de suas experiências de vida (e não uma caixa vazia onde deve ser depositado o conhecimento); que precisa entender/questionar as estruturas à sua volta;

\footnotetext{
${ }^{1}$ Citação original: critical information literacy is a library instruction praxis that promotes critical engagement with information sources, considers students collaborators in knowledge production practices (and creators in their own right), recognizes the affective dimensions of research, and (in some cases) has liberatory aims.
} 
para poder se posicionar e se conscientizar de seu papel ativo no mundo; que contém seus limites; para que então possa agir no sentido de transformar a sociedade no lugar que ela/ele deseja que seja.

A partir do ponto de vista da pedagogia crítica, a competência em informação, para ser libertadora, precisa construir conhecimento e não treinar. Trata-se mais de um despertar, de uma sensibilização ao fato da informação ser socialmente construída em relações intersubjetivas entre sujeitos, registros e contextos.

Por esse ângulo, a pessoa não somente adquire habilidades, mas também aprende a ter o hábito de questionar origens/interesses/contexto de produção da informação. A pessoa nunca se torna competente: ela desenvolve continuamente sua competência, sempre em relação dialética com os condicionantes sócio-político-econômico-tecnológicoculturais à sua volta. Como os contextos estão sempre mudando, com eles deve mudar a nossa compreensão da produção, disseminação e uso da informação.

Na definição de competência crítica em informação analisada, a pedagogia freireana corresponde tanto a) ao método, quando "considera estudantes como colaboradores em práticas de produção de conhecimento (e criadores em seu próprio direito)"; quanto b) aos objetivos de emancipação social presentes no final "e (em alguns casos) tem objetivos libertadores" (ACCARDI, DRABINSKI; KUMBIER, 2010, p. xiii, tradução nossa).

Ainda na mesma citação, já o trecho que "reconhece as dimensões afetivas da pesquisa", nos remete por um lado, ao conceito de serendipity que significa deixar um espaço para o acaso, para o encontro fortuito com algo interessante pelo qual nunca procuraríamos. Além disso, atenta para a questão humana do fazer educacional e científico, que passa invariavelmente pelas alegrias e turbulências das relações pessoais de amizade, familiares, de saúde, entre outras. Tal preocupação faz parte de uma pedagogia voltada para o fomento de modos de agir empáticos e dialoga com elementos criativos e emocionais levantados por Vitorino e Piantola (2009).

Diante desse olhar para a conformação da linha de atuação da $\mathrm{CCl}$ estadunidense, apresentamos um panorama da produção nacional em torno do conceito.

\section{METODOLOGIA}

A presente pesquisa é um levantamento bibliográfico de natureza descritiva e exploratória que olha para os estudos sobre competência crítica em informação, a partir da literatura produzida sobre o tema no Brasil. Os dados foram coletados na Base de Dados Referencial de Artigos de Periódicos em Ciência da Informação (BRAPCI) e na Biblioteca Digital de Teses e Dissertações (BDTD) com o descritor "competência crítica em informação".

As bases selecionadas têm cobertura nacional ampla e são usualmente empregadas em levantamentos bibliográficos no campo da Ciência da Informação. Como qualquer outra opção metodológica, essa tem suas limitações, sendo a principal delas seu caráter não sistemático. Temos conhecimento de outros trabalhos que tratam da temática e que não se encontram referenciados nessas duas bases, mas entendemos que nosso objetivo, a saber, apresentar um panorama geral não exaustivo, mas representativo, fica contemplado pela metodologia.

O primeiro artigo referenciado pela BRAPCl é de 2016 e a pesquisa foi concluída no início de 2021, com publicações referentes ao ano de 2020. Dessa forma, ela cobre pesquisas realizadas nesses primeiros 5 anos de desenvolvimento do campo, ou seja, meia década, em referência ao artigo de Eamon Tewell (2015) já mencionado. 
Não se encaixa no nosso escopo de pesquisa as análises de citações ou as redes de co-autoria, métricas muito usadas na $\mathrm{Cl}$ para mapear produções científicas, por entendermos que elas não nos ajudam a identificar os tipos de pesquisas realizadas ou as práticas de ensino eventualmente desenvolvidas.

Os resultados indicam 23 artigos e 3 dissertações de mestrado sobre o tema. Para as dissertações, fizemos um breve resumo do tema geral da pesquisa e do uso do conceito. Já para os artigos, nos interessamos pelas suas temáticas e pelos tipos de pesquisa que eles relatam. As temáticas são representadas no quadro de resultados pelas palavras-chave usadas para representar as publicações. Já os tipos de pesquisa, foram classificados como teórica, empírica ou aplicada.

\subsection{Competência crítica em informação no Brasil}

A primeira pesquisa de pós-graduação sobre o tema da competência crítica em informação foi a dissertação de mestrado de Anna Brisola (2016) intitulada "A ágora digital, a competência crítica em informação e a cidadania ampliada: uma construção possível". A autora evidencia a relação entre competência em informação, pensamento crítico e participação cidadã no novo milênio, sublinhando a importância de uma atitude crítica que favoreça o despertar do gosto informacional e da busca pelo conhecimento em uma sociedade midiática e digitalizada.

No ano seguinte, Andréa Doyle (2017) produz a dissertação "Competência crítica em informação nas escolas ocupadas do Rio de Janeiro". A autora estuda a circulação de informações no movimento estudantil que ocupou suas escolas, usando a competência crítica em informação com fio condutor para ligar espaços de informação, fontes de informação, modos de aprender, atuação política e emancipação.

Em 2019, Daniela Alvez de Melo (2019) defende a dissertação "Práticas informacionais e a construção da competência crítica em informação: um estudo na Bamidelê - Organização de Mulheres Negras da Paraíba". A autora coloca a competência crítica em informação como ferramental de base para práticas de resistência à opressão histórica das mulheres negras na instituição analisada, a partir do desenvolvimento individual e coletivo e do fortalecimento mútuo de um senso crítico informacional.

As três primeiras pesquisas de dissertação sobre competência crítica em informação destacam a relação entre informação, política e empoderamento ${ }^{2}$ que é característica das teorias críticas. A primeira tem uma orientação mais ensaística e as duas seguintes são pesquisas de campo com abordagens similares que, entre outros métodos, usaram entrevistas semi-estruturadas com pessoas ativistas políticas para coletar dados e analisar suas práticas informacionais.

Já no que diz respeito aos textos publicados em periódicos ou em anais de congressos, a consulta à BRAPCl no dia 10 de fevereiro de 2021, usando o descritor "competência crítica em informação", encontrou 23 artigos. O quadro abaixo sistematiza seus títulos, autores, locais e anos de publicação. Coletamos suas palavras-chave para compreender os principais temas tratados nesses trabalhos.

A leitura dos resumos permitiu identificar quais dessas pesquisas tinham sido desenvolvidas a partir de um campo empírico ( $\mathrm{PE}=$ Pesquisa Empírica) e quais delas se

\footnotetext{
2 Empoderamento é entendido aqui na compreensão de Magdalena Léon não de um poder sobre outrem (dominação), mas de poder de (capacidade de ação), poder com (colaboração) e um poder para (resistir à opressão).
} 
relacionavam diretamente com o ensino/aprendizagem dessa competência $(E A=$ Ensino/Aprendizagem da $\mathrm{CCl}$ ).

Quadro 1 - Literatura sobre competência crítica em informação na BRAPCl em fevereiro de 2021

\begin{tabular}{|c|c|c|c|c|c|c|}
\hline Autoras/es & Ano & Título & Periódico/Evento & Palavras-chave & PE* & $\mathrm{EA}^{* *}$ \\
\hline $\begin{array}{l}\text { DOYLE, Andréa; } \\
\text { BEZERRA, Arthur }\end{array}$ & 2016 & $\begin{array}{l}\text { (In)formação e cultura } \\
\text { nas escolas ocupadas } \\
\text { do Rio de Janeiro }\end{array}$ & $\begin{array}{l}\text { Pesquisa Brasileira } \\
\text { em Ciência da } \\
\text { Informação e } \\
\text { Biblioteconomia }\end{array}$ & $\begin{array}{l}\text { Ocupação. } \\
\text { Competência } \\
\text { crítica em } \\
\text { informação. Edu- } \\
\text { cação. Cultura. } \\
\text { Ensino Médio. }\end{array}$ & Sim & Não \\
\hline $\begin{array}{l}\text { FIGUEIREDO, } \\
\text { Márcia Feijão de. }\end{array}$ & 2016 & $\begin{array}{l}\text { Ferramentas no } \\
\text { julgamento avaliativo } \\
\text { em ambiente web } \\
\text { para buscas com } \\
\text { vistas ao } \\
\text { desenvolvimento de } \\
\text { competência crítica } \\
\text { em informação }\end{array}$ & $\begin{array}{l}\text { Revista Conhecimen- } \\
\underline{\text { to em Ação }}\end{array}$ & $\begin{array}{l}\text { Ciência da } \\
\text { Informação. } \\
\text { Biblioteconomia. } \\
\text { Competência em } \\
\text { Informação. Bus- } \\
\text { ca da Informação. } \\
\text { Julgamento } \\
\text { Avaliativo. }\end{array}$ & Não & Não \\
\hline $\begin{array}{l}\text { BEZERRA, Arthur } \\
\text { Coelho; DOYLE, } \\
\text { Andréa }\end{array}$ & 2017 & $\begin{array}{l}\text { Competência crítica } \\
\text { em informação e } \\
\text { participação ética em } \\
\text { comunidades de } \\
\text { aprendizagem }\end{array}$ & $\begin{array}{l}\text { XVIII ENANCIB, } 2017 . \\
\text { (Gt-1 - Estudo } \\
\text { Histórico e } \\
\text { Epistemológico da } \\
\text { Ciência da } \\
\text { Informação - } \\
\text { Comunicação Oral) }\end{array}$ & $\begin{array}{l}\text { Competência em } \\
\text { Informação. } \\
\text { Competência } \\
\text { Crítica em } \\
\text { Informação. Ética. } \\
\text { Framework for } \\
\text { Information Liter- } \\
\text { acy for Higher } \\
\text { Education. ACRL. }\end{array}$ & Não & Não \\
\hline $\begin{array}{l}\text { BRISOLA, Anna } \\
\text { Cristina; GOMES, } \\
\text { Josir Cardoso; } \\
\text { SCHNEIDER, } \\
\text { Marco André } \\
\text { Feldman }\end{array}$ & 2017 & $\begin{array}{l}\text { Hackeando dados } \\
\text { abertos: competência } \\
\text { crítica em informação } \\
\text { e cidadania }\end{array}$ & $\begin{array}{l}\text { XVIII ENANCIB, } 2017 . \\
\text { (Gt-5 - Política e } \\
\text { Economia da } \\
\text { Informação - } \\
\text { Comunicação Oral) }\end{array}$ & $\begin{array}{l}\text { Competência } \\
\text { Crítica em } \\
\text { Informação. Dado } \\
\text { Aberto. LAI. }\end{array}$ & Sim & Não \\
\hline $\begin{array}{l}\text { BRISOLA, Anna } \\
\text { Cristina; } \\
\text { SCHNEIDER, } \\
\text { Marco André } \\
\text { Feldman; SILVA } \\
\text { JúNIOR, Jobson } \\
\text { Francisco da }\end{array}$ & 2017 & $\begin{array}{l}\text { Competência crítica } \\
\text { em informação, ética } \\
\text { intercultural da } \\
\text { informação e } \\
\text { cidadania global na } \\
\text { era digital: } \\
\text { fundamentos e } \\
\text { complementaridades }\end{array}$ & $\begin{array}{l}\text { XVIII ENANCIB, } 2017 . \\
\text { (Gt-5 - Política e } \\
\text { Economia da } \\
\text { Informação - } \\
\text { Comunicação Oral) }\end{array}$ & $\begin{array}{l}\text { Ética em } \\
\text { Informação. } \\
\text { Competência } \\
\text { Crítica em } \\
\text { Informação. } \\
\text { Cidadania. Credi- } \\
\text { bilidade. }\end{array}$ & Não & Não \\
\hline
\end{tabular}




\begin{tabular}{|c|c|c|c|c|c|c|}
\hline Autoras/es & Ano & Título & Periódico/Evento & Palavras-chave & PE* & $\mathrm{EA}^{* *}$ \\
\hline $\begin{array}{l}\text { BEZERRA, Arthur } \\
\text { Coelho }\end{array}$ & 2018 & $\begin{array}{l}\text { Contribuição da } \\
\text { Teoria Crítica aos } \\
\text { estudos sobre regime } \\
\text { de informação e } \\
\text { competência crítica } \\
\text { em informação }\end{array}$ & $\begin{array}{l}\text { XIX ENANCIB, } 2018 . \\
\text { (Gt-1 - Estudo } \\
\text { Histórico e } \\
\text { Epistemológico da } \\
\text { Ciência da } \\
\text { Informação - } \\
\text { Comunicação Oral) }\end{array}$ & $\begin{array}{l}\text { Teoria Crítica. } \\
\text { Regime de } \\
\text { Informação. } \\
\text { Competência em } \\
\text { Informação. } \\
\text { Competência } \\
\text { Crítica em } \\
\text { Informação. Des- } \\
\text { informação. }\end{array}$ & Não & Não \\
\hline $\begin{array}{l}\text { BRISOLA, Anna } \\
\text { Cristina; } \\
\text { ROMEIRO, } \\
\text { Nathália Lima }\end{array}$ & 2018 & $\begin{array}{l}\text { A competência crítica } \\
\text { em informação como } \\
\text { resistência: uma } \\
\text { análise sobre o uso da } \\
\text { informação na } \\
\text { atualidade }\end{array}$ & $\begin{array}{l}\text { Revista Brasileira de } \\
\underline{\text { Biblioteconomia e }} \\
\underline{\text { Documentação }}\end{array}$ & $\begin{array}{l}\text { Competência } \\
\text { Crítica em } \\
\text { Informação. Ética. } \\
\text { Cidadania. } \\
\text { Desinformação. } \\
\text { Competência em } \\
\text { Informação. }\end{array}$ & Não & Não \\
\hline $\begin{array}{l}\text { BRISOLA, Anna; } \\
\text { BEZERRA, Arthur } \\
\text { Coelho }\end{array}$ & 2018 & $\begin{array}{l}\text { Desinformação e } \\
\text { circulação de "fake } \\
\text { news": distinções, } \\
\text { diagnóstico e reação }\end{array}$ & $\begin{array}{l}\text { XIX ENANCIB, 2018. } \\
\text { (Gt-5 - Política e } \\
\text { Economia da } \\
\text { Informação - } \\
\text { Comunicação Oral) }\end{array}$ & $\begin{array}{l}\text { Desinformação. } \\
\text { Fake News. } \\
\text { Competência } \\
\text { Crítica em } \\
\text { Informação. } \\
\text { Competência em } \\
\text { Informação. }\end{array}$ & Não & Não \\
\hline DOYLE, Andréa & 2018 & $\begin{array}{l}\text { Ideologia e } \\
\text { Competência Crítica } \\
\text { em Informação: um } \\
\text { olhar para } \\
\text { movimentos de } \\
\text { biblioteconomia } \\
\text { crítica }\end{array}$ & $\begin{array}{l}\text { Revista Folha de } \\
\underline{\text { Rosto }}\end{array}$ & $\begin{array}{l}\text { Competência } \\
\text { crítica em } \\
\text { informação. } \\
\text { Biblioteconomia } \\
\text { crítica. Ideologia. } \\
\text { Movimento so- } \\
\text { cial. Twitter. }\end{array}$ & Sim & Não \\
\hline $\begin{array}{l}\text { LEITE, Bruno } \\
\text { Ferreira; } \\
\text { PIMENTA, } \\
\text { Ricardo Medeiros }\end{array}$ & 2018 & $\begin{array}{l}\text { Contribuições da } \\
\text { Competência Crítica } \\
\text { em Informação para a } \\
\text { atuação em } \\
\text { preservação por } \\
\text { arquivistas e } \\
\text { bibliotecários }\end{array}$ & $\begin{array}{l}\text { XIX ENANCIB, 2018. } \\
\text { (Gt-10 - Informação } \\
\text { e Memória - } \\
\text { Comunicação Oral) }\end{array}$ & $\begin{array}{l}\text { Competência em } \\
\text { Informação. } \\
\text { Competência } \\
\text { Crítica em } \\
\text { Informação. } \\
\text { Preservação. } \\
\text { Arquivista. Bibli- } \\
\text { otecário. }\end{array}$ & Não & Não \\
\hline $\begin{array}{l}\text { OLIVEIRA, Maria } \\
\text { Lívia Pacheco de; } \\
\text { SOUZA, Edivanio } \\
\text { Duarte }\end{array}$ & 2018 & $\begin{array}{l}\text { A competência crítica } \\
\text { em informação no } \\
\text { contexto das fake } \\
\text { news: os desafios do } \\
\text { sujeito informacional } \\
\text { no ciberespaço }\end{array}$ & $\begin{array}{l}\text { XIX ENANCIB, 2018. } \\
\text { (Gt-1 - Estudo } \\
\text { Histórico e } \\
\text { Epistemológico da } \\
\text { Ciência da } \\
\text { Informação - } \\
\text { Comunicação Oral) }\end{array}$ & $\begin{array}{l}\text { Competência } \\
\text { Crítica em } \\
\text { Informação. Fake } \\
\text { News. Sujeito } \\
\text { Informacional. }\end{array}$ & Não & Não \\
\hline
\end{tabular}




\begin{tabular}{|c|c|c|c|c|c|c|}
\hline Autoras/es & Ano & Título & Periódico/Evento & Palavras-chave & PE* & $\mathrm{EA}^{* *}$ \\
\hline $\begin{array}{l}\text { ROMEIRO, } \\
\text { Nathália Lima; } \\
\text { SILVA, Franciéle } \\
\text { Carneiro Garcês } \\
\text { da; BRISOLA, } \\
\text { Anna Cristina } \\
\text { Caldeira de } \\
\text { Andrada Sobral }\end{array}$ & 2018 & $\begin{array}{l}\text { A página arrumando } \\
\text { letras como um } \\
\text { espaço para a } \\
\text { desconstrução da } \\
\text { dominação do } \\
\text { patriarcado }\end{array}$ & $\begin{array}{l}\text { Revista Digital de } \\
\text { Biblioteconomia \& } \\
\text { Ciência da } \\
\underline{\text { Informação }}\end{array}$ & $\begin{array}{l}\text { Ciência da } \\
\text { Informação. Ética. } \\
\text { Patriarcado. } \\
\text { Mídia Social. } \\
\text { Cultura Musical. } \\
\text { Gênero. Com- } \\
\text { petência Crítica } \\
\text { em Informação. }\end{array}$ & Sim & Não \\
\hline $\begin{array}{l}\text { VEIGA, Miriã } \\
\text { Santana; } \\
\text { PIMENTA, Jussara } \\
\text { Santos; SILVA, } \\
\text { Luciana Semeão } \\
\text { da }\end{array}$ & 2018 & $\begin{array}{l}\text { O desafio educacional } \\
\text { do bibliotecários nas } \\
\text { bibliotecas multiníveis } \\
\text { da rede federal de } \\
\text { educação profissional, } \\
\text { científica e } \\
\text { tecnologica }\end{array}$ & Biblionline & $\begin{array}{l}\text { Letramento } \\
\text { informacional. } \\
\text { Bibliotecário. } \\
\text { Educação } \\
\text { profissional. }\end{array}$ & Sim & Sim \\
\hline $\begin{array}{l}\text { ARRUDA, } \\
\text { Anderson } \\
\text { Matheus Alves; } \\
\text { ALVES, Adriana } \\
\text { Lopes }\end{array}$ & 2019 & $\begin{array}{l}\text { Construções } \\
\text { epistemológicas e o } \\
\text { papel do sujeito ativo } \\
\text { no processo da } \\
\text { informação a partir da } \\
\text { competência crítica } \\
\text { em informação: uma } \\
\text { análise de caso }\end{array}$ & $\begin{array}{l}\text { Revista Conhecimen- } \\
\text { to em Ação }\end{array}$ & $\begin{array}{l}\text { Ciência da } \\
\text { Informação. } \\
\text { Competência } \\
\text { Crítica em } \\
\text { Informação. Par- } \\
\text { adigma Social. } \\
\text { Processo Infor- } \\
\text { macional. }\end{array}$ & Sim & Não \\
\hline $\begin{array}{l}\text { BELONI, Aneli; } \\
\text { BEZERRA, Arthur } \\
\text { Coelho }\end{array}$ & 2019 & $\begin{array}{l}\text { Competência crítica } \\
\text { em informação e ética } \\
\text { em big data }\end{array}$ & $\begin{array}{l}\text { XX ENANCIB, } 2019 . \\
\text { (Gt } 5 \text { - Política e } \\
\text { Economia da } \\
\text { Informação) }\end{array}$ & $\begin{array}{l}\text { Big Data; } \\
\text { Competência } \\
\text { Crítica em } \\
\text { Informação; } \\
\text { Competência em } \\
\text { Informação; } \\
\text { Ética. }\end{array}$ & Não & Não \\
\hline $\begin{array}{l}\text { BEZERRA, Arthur } \\
\text { Coelho; BELONI, } \\
\text { Aneli }\end{array}$ & 2019 & $\begin{array}{l}\text { Os sentidos da } \\
\text { "crítica" nos estudos } \\
\text { de competência em } \\
\text { informação }\end{array}$ & Em Questão & $\begin{array}{l}\text { Ciëncia Social } \\
\text { Aplicada. Ciência } \\
\text { da Informação. } \\
\text { Competência em } \\
\text { Informação. } \\
\text { Competência } \\
\text { Crítica em } \\
\text { Informação. Teor- } \\
\text { ia Crítica. Filosofia } \\
\text { Crítica. Pedagogia } \\
\text { Crítica. }\end{array}$ & Sim & Não \\
\hline
\end{tabular}




\begin{tabular}{|c|c|c|c|c|c|c|}
\hline Autoras/es & Ano & Título & Periódico/Evento & Palavras-chave & PE* & $\mathrm{EA}^{* *}$ \\
\hline $\begin{array}{l}\text { BEZERRA, Arthur } \\
\text { Coelho; SCHNEID } \\
\text { ER, Marco André } \\
\text { Feldman; SALDAN } \\
\text { HA, Gustavo Silva }\end{array}$ & 2019 & $\begin{array}{l}\text { Competência crítica } \\
\text { em informação como } \\
\text { crítica à competência } \\
\text { em informação }\end{array}$ & $\begin{array}{l}\text { Informação \& } \\
\text { Sociedade: Estudos }\end{array}$ & $\begin{array}{l}\text { Competência } \\
\text { crítica em } \\
\text { informação. } \\
\text { Competência em } \\
\text { informação. } \\
\text { Teoria crítica. } \\
\text { Emancipação } \\
\text { social. }\end{array}$ & Não & Não \\
\hline $\begin{array}{l}\text { LOPES, Bianca da } \\
\text { Costa Maia; } \\
\text { BEZERRA, Arthur } \\
\text { Coelho }\end{array}$ & 2019 & $\begin{array}{l}\text { Entre } \\
\text { hiperinformação e } \\
\text { desinformação: o "fio } \\
\text { de ariadne" para a } \\
\text { preservação da } \\
\text { informação na web }\end{array}$ & Liinc em revista & $\begin{array}{l}\text { Hiperinformação; } \\
\text { Memória; } \\
\text { Preservação; } \\
\text { Competência } \\
\text { Crítica em } \\
\text { Informação; Era } \\
\text { Digital. }\end{array}$ & Não & Não \\
\hline $\begin{array}{l}\text { MELO, Daniella } \\
\text { Alves de; ROCHA, } \\
\text { Paullini Mariele } \\
\text { da Silva; ALVES, } \\
\text { Edvaldo Carvalho; } \\
\text { BRASILEIRO, } \\
\text { Fellipe Sá }\end{array}$ & 2019 & $\begin{array}{l}\text { Práticas } \\
\text { informacionais e a } \\
\text { competência crítica } \\
\text { em informação }\end{array}$ & $\begin{array}{l}\text { XX ENANCIB, 2019. } \\
\text { (Gt } 3 \text { - Mediação, } \\
\text { Circulação e } \\
\text { Apropriação da } \\
\text { Informação) }\end{array}$ & $\begin{array}{l}\text { Práticas } \\
\text { informacionais; } \\
\text { Competência } \\
\text { crítica em } \\
\text { informação; } \\
\text { Feminismo negro; } \\
\text { Bamidelê. }\end{array}$ & Sim & Não \\
\hline $\begin{array}{l}\text { BEZERRA, Arthur } \\
\text { Coelho }\end{array}$ & 2020 & $\begin{array}{l}\text { Da teoria matemática } \\
\text { para uma proposta de } \\
\text { teoria crítica da } \\
\text { informação: a } \\
\text { integração dos } \\
\text { conceitos de regime } \\
\text { de informação e } \\
\text { competência crítica } \\
\text { em informação }\end{array}$ & $\begin{array}{l}\text { Perspectivas em } \\
\text { Ciência da } \\
\text { Informação }\end{array}$ & $\begin{array}{l}\text { Teoria crítica da } \\
\text { informação; } \\
\text { Teoria } \\
\text { matemática da } \\
\text { comunicação; } \\
\text { Regime de } \\
\text { informação; } \\
\text { Competência } \\
\text { crítica em } \\
\text { informação; } \\
\text { Competência em } \\
\text { informação. }\end{array}$ & Não & Não \\
\hline $\begin{array}{l}\text { BRISOLA, Anna } \\
\text { Cristina; RAMOS } \\
\text { JUNIOR, Maurício }\end{array}$ & 2020 & $\begin{array}{l}\text { O bibliotecário como } \\
\text { um fator estratégico } \\
\text { de marketing e de } \\
\text { aprimoramento da } \\
\text { competência crítica } \\
\text { em informação }\end{array}$ & $\begin{array}{l}\text { Revista Brasileira de } \\
\text { Biblioteconomia e } \\
\text { Documentação }\end{array}$ & $\begin{array}{l}\text { Biblioteca. Compe } \\
\text { tência Crítica em } \\
\text { Informação. Infor } \\
\text { ma- } \\
\text { ção. Diálogo. Mar } \\
\text { keting. }\end{array}$ & Não & Não \\
\hline
\end{tabular}




\begin{tabular}{|c|c|c|c|c|c|c|}
\hline Autoras/es & Ano & Título & Periódico/Evento & Palavras-chave & PE* & $\mathrm{EA}^{* *}$ \\
\hline $\begin{array}{l}\text { FERREIRA, João } \\
\text { Rodrigo Santos; } \\
\text { LIMA, Paulo } \\
\text { Ricardo Silva; } \\
\text { SOUZA, Edivanio } \\
\text { Duarte }\end{array}$ & 2020 & $\begin{array}{l}\text { Desinformação, } \\
\text { infodemia e caos } \\
\text { social: impactos } \\
\text { negativos das fake } \\
\text { news no cenário da } \\
\text { COVID-19 }\end{array}$ & Em Questão & $\begin{array}{l}\text { Caos social. } \\
\text { Competência em } \\
\text { Informação. CO- } \\
\text { VID-19. Desin- } \\
\text { formação. Fake } \\
\text { news. Infodemia }\end{array}$ & Não & Não \\
\hline $\begin{array}{l}\text { MELO, Daniella } \\
\text { Alves de; ALVES, } \\
\text { Edvaldo Carvalho; } \\
\text { BRASILEIRO, } \\
\text { Fellipe Sá }\end{array}$ & 2020 & $\begin{array}{l}\text { Práticas } \\
\text { Informacionais das } \\
\text { mulheres negras }\end{array}$ & $\begin{array}{l}\text { Revista Folha de } \\
\text { Rosto }\end{array}$ & $\begin{array}{l}\text { Práticas } \\
\text { Informacionais. } \\
\text { Competência } \\
\text { Crítica em } \\
\text { Informação. } \\
\text { Bamidelê. }\end{array}$ & Sim & Não \\
\hline
\end{tabular}

Fonte: Elaborado pela autora (2021). Legenda: ${ }^{*} \mathrm{PE}=$ Pesquisa Empírica $/{ }^{* *} \mathrm{EA}=$ Ensino/Aprendizagem

Foram referenciados 2 trabalhos em 2016, 3 em 2017, 8 em 2018, 5 em 2019 e 4 em 2020 o que indica uma linha de pesquisa em início de desenvolvimento. Há que se considerar que os anais do Enancib são uma importante fonte de alimentação da BRAPCI, sendo que os do ano de 2019 ainda não estão referenciados, o que indica a existência mais trabalhos com o tema publicados nesse ano. Além disso, em 2020 houve a pandemia do novo Coronavírus que transformou a realidade mundial e acadêmica e não houve Enancib, o que indica novamente que mais trabalhos teriam sido acrescentados a esse corpus. A partir dessas considerações, apesar de números decrescentes nos dois últimos anos, entendemos o campo em expansão.

Sobre as pesquisas empíricas e aquelas relacionadas com o ensino de competências, o resultado mostrou uma maioria de pesquisas teóricas. Dos 23 trabalhos recuperados, 14 deles ou $61 \%$ do total é estritamente teórico; 9 trabalhos ou $39 \%$ têm um campo empírico e apenas 1 trabalho do total de pesquisas trata do ensino de competências em informação.

O artigo de autoria de Veiga, Pimenta e Silva (2018, p. 12) é o relato de uma pesquisa feita nas bibliotecas do IFRO (Instituto Federal de Rondônia). As autoras, que consideram que "educar informacionalmente um aluno é incentivá-lo a ter um senso crítico da informação que recebe e que dispõe para a sociedade", viram que quase metade do corpo de profissionais da biblioteconomia nunca recebeu orientações sobre ações educativas. A partir das pesquisas documentais e entrevistas, elas desenvolveram, junto com as equipes das bibliotecas, uma proposta de incentivo ao letramento informacional, num trabalho colaborativo, dando um passo importante para a formação pedagógica dessas equipes.

As atividades propostas pelo grupo de trabalho coordenado por Veiga, Pimenta e Silva (2018) incluem cursos de normalização e de uso do Portal de Periódicos da Capes. Enquanto concordamos que essas atividades são importantes para o fazer científico e que desenvolvem a competência em informação, elas não parecem se alinhar com as questões de justiça e emancipação social que caracterizam a linha teórica da $\mathrm{CCl}$. De acordo com a descrição do artigo, elas são exclusivamente voltadas para treinamentos e normas técnicas, sem os necessários questionamentos das estruturas de poder em torno dos sistemas de informação.

Nossa leitura é que as autoras deram um primeiro passo fundamental, que prepara o campo dos estudos informacionais para desenvolver práticas de ensino das competências 
em informação com esse olhar crítico. Elas percebem a necessidade de formação pedagógica das equipes das unidades de informação e realizam um trabalho participativo e horizontal que condiz com a pedagogia crítica de Paulo Freire (1987). Por outro lado, o produto desse trabalho, os cursos e treinamentos que elas propõem, carecem de questionamentos políticos e objetivos libertadores que distinguem essa linha da $\mathrm{CCl}$, não podendo ser considerado como um exemplo de ensino de competência crítica em informação.

Mas então, se a competência crítica em informação no Brasil não discute métodos de ensino libertadores, de que ela trata? Os temas já abordados por pesquisas publicadas no Brasil, coletados pelas palavras-chave usadas para indexar os artigos, estão representados abaixo pela nuvem de palavras.

Figura 1 - Nuvem de palavras-chave da literatura sobre Competência Crítica em Informação na BRAPCl em fevereiro de 2021

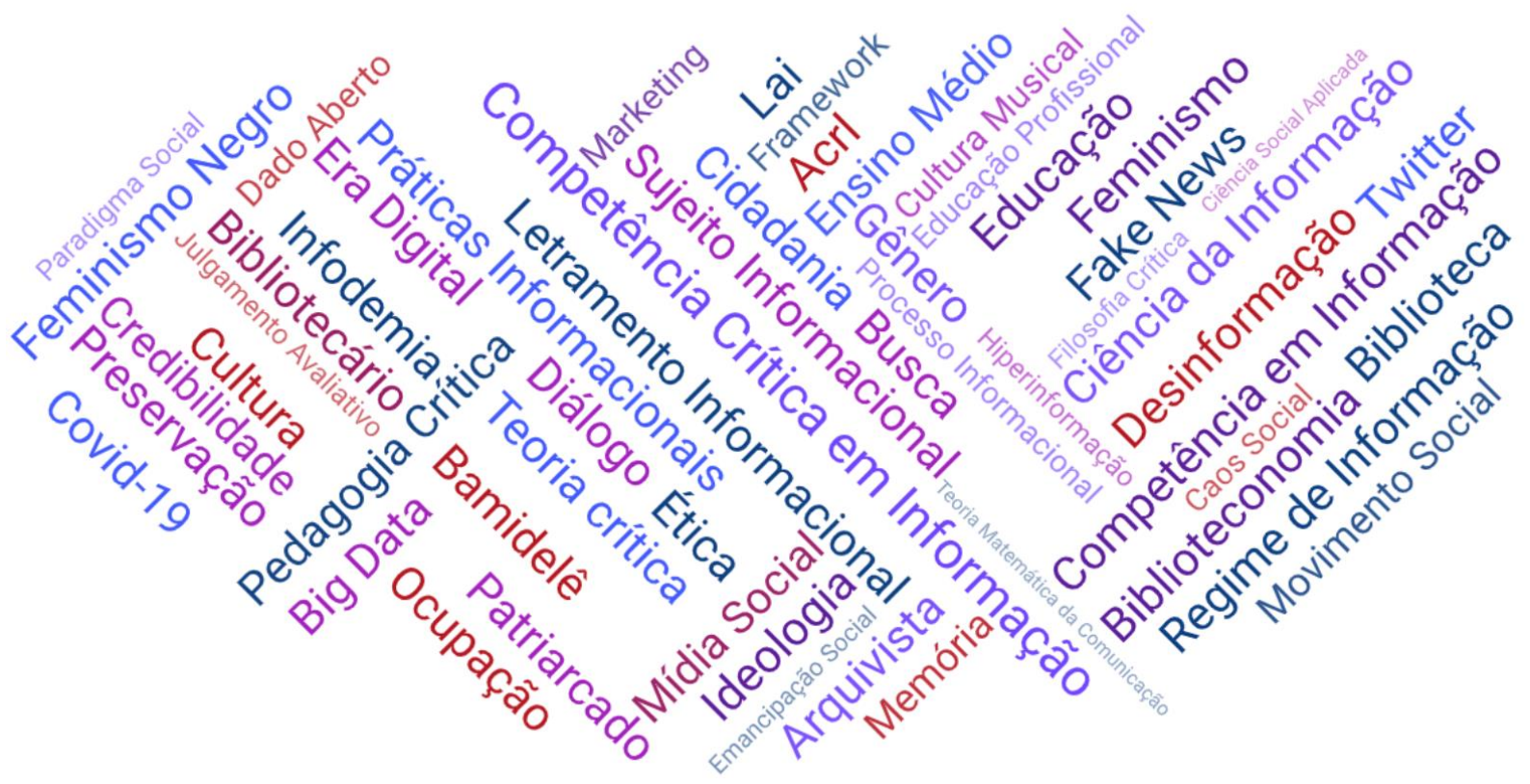

Fonte: Elaborado pela autora (com wordart.com) em 2021.

Foram contabilizadas 55 palavras-chave no levantamento da literatura relacionado no quadro 1, sendo competência crítica em informação a principal com 20 ocorrências, seguida de competência em informação com 12. A palavra-chave Ética aparece 5 vezes; Ciência da Informação e Desinformação vêm com 4 ocorrências cada, seguidas de Fake News e Teoria Crítica com 3; Biblioteconomia, Cultura, Cidadania, Bibliotecário, Práticas Informacionais, Preservação, Regime de Informação e Bamidelê contam 2 ocorrências cada uma. Os 40 demais termos aparecem apenas uma vez.

Vemos a Ética, Desinformação, Fake News, Hiperinformação e Infodemia como o campo semântico de destaque, sugerindo a competência crítica em informação como elemento codependente de princípios éticos para o combate à desinformação. Outro tema de destaque é o universo da biblioteca e instituições de informação que aparece também com termos Biblioteca, Biblioteconomia, Bibliotecário, e Arquivista, acompanhados de termos Cultura, Preservação, Memória, Práticas Informacionais e Processo Informacional. 
Com três ocorrências, o termo Teoria Crítica vem se colocar como fundamento da CCI e traz consigo termos Pedagogia Crítica e Filosofia Crítica. Já o nome Bamidelê, uma instituição de acolhimento e militância pelos direitos das mulheres negras, aparece em dois trabalhos e evidencia outros termos referentes aos estudos de gênero e sexualidade como Gênero, Patriarcado, Feminismo e Feminismo Negro. A ideia de Regime de Informação acompanhada dos termos Emancipação Social, Cidadania e Movimento Social reforçam essa tendência política dos estudos de $\mathrm{CCl}$.

Com apenas uma ocorrência, temas como Big Data, LAl, Dados Abertos marcam presença indicando um caminho para o estudo da Ciência Aberta, assim como a Mídia Social, Twitter e Era Digital apontam para interseções tecnológicas. Por fim, de fundamental importância para o presente trabalho, os termos Educação, Ensino Médio, Educação Profissional e Diálogo remetem ao universo do ensino/aprendizagem para o qual estamos dando um foco especial.

\section{DISCUSSÃO SOBRE LÓCUS E CONSIDERAÇÕES FINAIS}

Nos Estados Unidos, foi dentro das bibliotecas escolares e universitárias que o conceito de competência crítica em informação se desenvolveu e continua sendo pensado. Ou seja, é nas bibliotecas e nas aulas dadas por pessoas bibliotecárias que se propaga a ideia de uma competência em informação voltada para a conscientização das pessoas sobre o papel social da informação no mundo e, consequentemente, para sua transformação na direção da justiça social.

Mais especificamente, foi na atividade de educação para a competência em informação, ou seja, na interseção da biblioteconomia com a docência que os primeiros questionamentos e as primeiras soluções práticas surgiram. Daí se entende a forte presença do pensamento de Paulo Freire, seja pela perspectiva construtivista de educação ou pela conscientização dos sujeitos para a autonomia, no processo de promoção do acesso, uso, produção e disseminação informacional.

Já no Brasil, o conceito de competência crítica em informação, tem sido trabalhado notadamente por pesquisadoras e pesquisadores em Ciência da Informação, dentro de uma perspectiva teórica de pesquisa, e não de uma perspectiva aplicada. Nos estudos brasileiros, observa-se uma tendência ao uso conceitual da competência crítica em informação mais como um modelo argumentativo, além da crítica aos modelos mecânicos de algumas práticas de Colnfo, presentes em ambos os países.

Nesse período inicial da pesquisa nacional sobre o tema (2016-2020), nota-se o desenvolvimento de estudos variados sobre temas como educação revolucionária, cidadania digital, gosto informacional, ética da informação, para citar alguns dos temas dos trabalhos listados na subseção anterior. a A revisão de literatura também mostrou que ainda não há pesquisas que detalham exemplos de um ensino crítico das competências em informação.

O desenvolvimento do campo no Brasil gerou uma particularidade técnica de recuperação da informação. O termo 'critical information literacy' é recuperado tanto em buscas por 'critical information literacy' quanto por 'information literacy'. Já o termo "competência crítica em informação", em que a palavra crítica está no meio da expressão, inviabiliza a recuperação dos trabalhos da linha crítica pelas pessoas que buscam o termo "competência em informação".

A escolha do termo brasileiro gerou um nicho de pesquisa mais ou menos isolado do acúmulo de duas décadas de pesquisas sobre competência em informação no país, criando 
uma dificuldade para a irradiação do debate crítico na comunidade acadêmica. Para contornar esse problema, quando há interesse no diálogo, os trabalhos têm sido representados com ambos os descritores "competência crítica em informação" e "competência em informação", conforme aparece na revisão de literatura.

Por outro lado, a principal vantagem do lócus onde o conceito de competência crítica em informação se desenvolveu é a amplitude da compreensão brasileira de Ciência da Informação como ciência transversal a todas as outras.

A Ciência da Informação que se faz hoje é muito diferente daquela de cinco décadas atrás (...) porque o desenvolvimento das tecnologias solucionou uma série de problemas, mas trouxe muitos outros, relativos às questões humanas (sociais, culturais, políticas, econômicas, jurídicas) de como nós, seres humanos, no século XXI, produzimos, fazemos circular, disseminamos, organizamos, preservamos, usamos e nos apropriamos dos registros do conhecimento produzidos, bem como intervimos, criando instituições, serviços e produtos, nos fluxos informacionais (ARAÚJO, 2018, p. 7).

O entendimento da $\mathrm{Cl}$ como campo de científico que se ocupa de todas as questões que circundam os registros do conhecimento e os fluxos informacionais a coloca no centro dos principais desafios da contemporaneidade. Qualquer pessoa hoje é, ao mesmo tempo, produtora, mediadora e consumidora de informação. Mais ainda, isso não acontece de forma esporádica ou eventual, para atender a uma necessidade de informação específica, mas de forma contínua, ininterrupta, e frequentemente até involuntária.

O ambiente informacional também precisa ser considerado em suas dimensões econômicas, políticas, legais, culturais e sociais. Desde o cinturão de satélites e da fibra óptica da infraestrutura da internet, passando pelas sobreviventes dos conglomerados de mídia (Disney, Time Warner, 21 Century Fox e CBS) do hardware (Apple, Microsoft e Intel) e da telefonia (AT\&T, Telefonica), pelas gigantes das plataformas (Google, Facebook, Amazon, Netflix) até os robôs aspiradores e a internet das coisas (IOT), a onipresença das tecnologias de informação e comunicação (TIC) na sociedade é incontestável.

As considerações sobre propriedade, comercialização e direitos sobre obras e dados, assim como a representatividade de grupos minorizados ou vulneráveis nos espaços de discussão e poder nas universidades, na política e na gestão empresarial são temas que podem ser explorados a partir do estudo da $\mathrm{CCl}$. O desenvolvimento de um conjunto de atitudes questionadoras e atentas com relação à informação e ao ambiente informacional pode contribuir para o empoderamento, para a cidadania e para o bem viver.

A presente revisão indica que a competência crítica em informação se delineia na interseção entre informação, política e justiça social, tendo fundamentos nas teorias críticas e objetivos de emancipação de pessoas informadas e responsáveis pela informação que acessam, mobilizam, produzem e compartilham. A subárea da $\mathrm{CCl}$, com suas particularidades locais, tem muito a contribuir para os desafios contemporâneos, mas ainda se apresenta como um nicho teórico. Se ganhar capilaridade por bibliotecas, arquivos, museus e, principalmente, salas de aula poderá se traduzir em práticas de ensino-aprendizagem que promovam um relacionamento crítico com a informação nas diversas esferas da vida social. 


\section{REFERÊNCIAS}

ACCARDI, M.; DRABINSKI, E.; KUMBIER, A.. Critical Library Instruction: Theories and Methods Illustrated Edition. Sacramento, Califórnia: Library Juice Press, 2010.

ARAÚJO, C. A. O que é ciência da informação. Belo Horizonte: KMA, 2018.

BEZERRA, A. C. Vigilância e filtragem de conteúdo nas redes digitais: desafios para a competência crítica em informação. In: ENCONTRO NACIONAL DE PESQUISA EM CIÊNCIA DA INFORMAÇÃO, 16, 2015, João Pessoa. Anais... João Pessoa: ANCIB, 2015 Disponível em: http://www.ufpb.br/evento/lti/ocs/index.php/enancib2015/enancib2015/paper/viewFile/2 716/1034 Acesso em: 20 jul. 2017.

BRISOLA, A. A ágora digital, a competência crítica em informação e a cidadania ampliada: uma construção possível.148 f. Dissertação (Mestrado em Ciência da Informação) Programa de Pós-Graduação em Ciência da Informação - Instituto Brasileiro de Informação em Ciência e Tecnologia, Universidade Federal do Rio de Janeiro, Escola de Comunicação, Rio de Janeiro, 2016. Disponível em: http://ridi.ibict.br/handle/123456789/890. Access: April 2019.

CROW, S. Information Literacy: What's Motivation Got to Do with It?. Chicago: Knowledge Quest. 35. 48-52, 2007. Disponível em: https://www.proquest.com/docview/194730488 Acesso em: jun. 2021

DOHERTY, J. J. Giving voice to the silenced: an essay in support of information literacy. Library Philosophy and Practice, p. 1-8, jun. 2007. Disponível em:

https://www.researchgate.net/publication/28166347 No Shhing Giving Voice to the Sile nced An Essay in Support of Critical Information Literacy

DOWNEY, A. Critical information literacy: foundations, inspiration and ideas. Sacramento, CA: Library Press Juice, 2016.

DOYLE, A. Competências em informação, mídia e tecnologias digitais e a desconstrução de estereótipos de gênero: práticas de ensino críticas. Tese (Doutorado em Ciência da Informação) - Programa de Pós-Graduação em Ciência da Informação, Universidade Federal do Rio de Janeiro, Instituto Brasileiro de Informação em Ciência e Tecnologia. IBICT/UFRJ, Rio de Janeiro, 2021.

DOYLE, A. Competência crítica em informação nas escolas ocupadas do Rio de Janeiro. 2017. 137 f. Dissertação (Mestrado em Ciência da Informação) - Programa de Universidade Federal do Rio de Janeiro, Instituto Brasileiro de Informação em Ciência e Tecnologia, Rio de Janeiro. Disponível em:

http://ridi.ibict.br/bitstream/123456789/960/1/Dissertacao AndreaDoyle Capa Dura.pdf. Acesso em: jun. 2019.

ELMBORG, J. Critical information literacy: implications for instructional practice. The Journal of Academic Librarianship, v. 32, n. 2, p. 192-199, mar. 2006. DOI

https://doi.org/10.1016/i.acalib.2005.12.004 
FREIRE, P. Pedagogia do oprimido. Rio de Janeiro: Paz e Terra, 1987.

MELO, D. Práticas informacionais e a construção da competência crítica em Informação: um estudo na Bamidelê - Organização de Mulheres Negras da Paraíba. 2019. 118 f. Dissertação (Mestrado em Ciência da Informação) - Universidade Federal da Paraíba, João Pessoa, 2019.

TEWELL, E. A decade of critical information literacy. Communications in Information Literacy, v. 9, n. 1, p. 24-43, 2015. DOI 10.15760/comminfolit.2015.9.1.174 Acesso em: jun. 2021.

VEIGA, M.; PIMENTA, J. S.; SILVA, L. S. da. O desafio educacional do bibliotecários nas bibliotecas multiníveis da rede federal de educação profissional, científica e tecnologica. Biblionline, v. 14, n. 4, p. 49-64, 2018. Disponível em:

https://periodicos.ufpb.br/ojs2/index.php/biblio/article/view/42957/21977. Acesso em: out. 2020.

VITORINO, E. V.; PIANTOLA, D. Competência informacional - bases históricas e conceituais: construindo significados. Ciência da Informação, Brasília, v. 38, n.3, p.130-141, set./dez., 2009. Disponível em: http://www.scielo.br/pdf/ci/v38n3/v38n3a09.pdf. Acesso em: set. 2015.

WARD, D. Re-visioning Information Literacy for Lifelong Meaning. Faculty and Staff Publications - Milner Library. 38, 2006. Acesso em: https://ir.library.illinoisstate.edu/fpml/38 Acesso em: jun. 2021 